\title{
Acesso à inovação - investigação, ética médica, direitos dos doentes e recursos financeiros
}

Access to innovation - research, medical ethics, patient rights and financial resources

Acceso a la innovación - investigación, ética médica, derechos del paciente y recursos financieros

Maria Paula Leite Ribeiro de Faria ${ }^{1}$

RESUMO: Este artigo trata da identificação dos direitos dos doentes em sede de acesso à inovação na área da saúde, e à conciliação entre estes direitos e os direitos dos outros doentes e a sustentabilidade do sistema de saúde. É legítimo ao Estado condicionar o acesso de doentes a tratamentos inovadores que podem traduzir a sua única hipótese de cura, ou uma melhoria substancial do seu estado de saúde, em nome de critérios de natureza económica? E esses critérios e decisões podem ser sujeitos ao controlo dos tribunais? Podem ser utilizados nesta ponderação de custos e de benefícios, critérios como a idade do doente, excluindo de certos tratamentos os doentes terminais ou em fim de vida? E se utilizarmos o direito à vida como argumento decisivo do acesso à inovação, garantindo o medicamento ou a tecnologia mais recente e mais cara, sempre que estiver em causa a sobrevivência do doente, não existe o perigo de prejudicar os que ainda têm hipóteses de cura, beneficiando quem já não pode retirar qualquer vantagem da inovação, e do gasto a ela associado? Uma vez que os recursos são limitados, sobretudo em épocas de crise financeira, a questão da sua distribuição constitui um problema que diz respeito a toda a sociedade, e que obriga a ponderar critérios de natureza jurídica, médica, financeira e política, e ética.

Palavras-chave: Alocação de recursos para a atenção à saúde. Prioridades em saúde. Recursos em saúde. Políticas públicas de saúde.

ABSTRACT: This article deals with the identification of patient's rights as regards the
access to innovation in health care, and the reconciliation of these rights and the rights of
other patients and the sustainability of the health system. Is it legitimate for the State to
restrain the access of patients to innovative treatments representing their only chance of
cure, or a substantial improvement in their health, in the name of economic criteria? These
criteria and decisions can be assessed by the courts? It is legitimate to use, in the
weighting of costs and benefits, criteria such as age of the patient, excluding the terminally
ill patients from the benefit of certain treatments? And if we use the right to life as the
decisive argument in the access to innovation, ensuring in all cases of survival, the newest
and most expensive technology, there is no risk of harming those patients who still have
healing perspectives? Since resources are limited, especially in times of financial crisis, the

\footnotetext{
${ }^{1}$ A autora é Professora Associada da Faculdade de Direito da Universidade Católica Portuguesa - Escola de Direito do Porto, é investigadora do CEID, Centro de Estudos e Investigação em Direito, da Faculdade de Direito da Universidade Católica Portuguesa, Portugal. Email: mfaria@porto.ucp.pt
} 
question of its distribution concerns the whole society, and requires the consideration of legal, medical, financial and political, and ethical criteria.

Keywords: Health care rationing. Health priorities. Health resources. Public health policies.

RESUMEN: Este artículo se ocupa de la identificación de los derechos de los pacientes en el acceso a la innovación en la asistencia sanitaria, así como la conciliación de estos derechos y los derechos de otros pacientes y la sostenibilidad del sistema de salud. ¿Es legítimo que el Estado limite el acceso de los pacientes a los tratamientos innovadores que puedan traducir su única posibilidad de curación, o una mejora sustancial en su salud, en nombre de criterios económicos? ¿Estos criterios y decisiones pueden estar sujetos al control de los tribunales? Pueden ser utilizados en esta ponderación de costes y beneficios, criterios como la edad del paciente, con exclusión de los enfermos terminales 0 en fin de vida de ciertos tratamientos? ¿Y si usamos el derecho a la vida como argumento decisivo en lo que respecta al acceso a la innovación, asegurando la tecnología más nueva y más cara donde está en juego la supervivencia del paciente, no hay peligro de dañar a los pacientes curables, beneficiando a los que ya no se puede derivar ninguna ventaja de la innovación, y el gasto asociado a él? Dado que los recursos son limitados, especialmente en tiempos de crisis financiera, la cuestión de su distribución es un problema que concierne a toda la sociedad, y que requiere considerar criterios jurídicos, médicos, financieros y políticos, y éticos.

Palabras-llave: Asignación de recursos para la atención de salud. Prioridades en salud. Recursos en salud. Políticas públicas de salud.

\section{Introdução}

O problema da distribuição equitativa de recursos na área da saúde é extremamente complexo e coloca inúmeras questões, algumas das quais transcendem o âmbito do nosso trabalho, como a de saber se os cuidados de saúde públicos devem ser garantidos a todos, independentemente dos seus recursos e da possibilidade de aceder a sistemas privados de saúde, se a auto-colocação em risco por parte do doente deve ter reflexos na sua posição relativa face a outros doentes (o doente que sempre fumou para além do razoável, ou não usava cinto de segurança quando foi vítima do acidente de viação, deve ser tratado em igualdade de circunstâncias em relação a outro que sempre teve cuidados com a sua saúde, e que não se colocou numa posição abusiva em relação aos recursos da colectividade? (1), ou ainda, agora ao nível das opções fundamentais do Estado, se este não deve corrigir a desproporção existente entre o que gasta em intervenções e hospitalização e o que investe em medicina preventiva (campanhas anti tabágicas, vacinação, melhoria das condições sanitárias da população). 
A equidade em saúde pode ser definida como a ausência de diferenças sistemáticas, e potencialmente evitáveis, em um ou mais aspectos da saúde, entre grupos populacionais caracterizados social, geográfica ou demograficamente. Neste contexto, um aspecto fundamental é o acesso a cuidados de saúde de qualidade em função das necessidades clínicas dos cidadãos (2)

Partindo do princípio de que não se encontra ainda suficientemente desenvolvido um critério de distribuição de recursos na área da saúde capaz de atender de forma equilibrada às diferenças sociais e económicas entre utentes (a este propósito não se esqueça que já se procede no nosso país à cobrança de taxas moderadoras de que estão isentas as camadas mais desfavorecidas da população, e que o serviço de saúde se deixa sustentar com base nos impostos pagos em proporção do rendimento e património de cada um, pelo que a justiça social neste domínio se encontra relativamente bem assegurada) o critério determinante do acesso aos cuidados de saúde deve ser o da necessidade clínica, ou seja, o critério da existência de indicação médica para a realização de uma intervenção ou tratamento. No entanto, esse critério pode não ser suficiente, onde está em causa o acesso à inovação, ou seja, o acesso a tratamentos e técnicas "de ponta", extremamente dispendiosos, que não podem ser garantidos de forma ilimitada a todos os cidadãos.

Prescindimos de tratar uma outra questão, a dizer de igual forma respeito à articulação entre os direitos individuais e a inovação no domínio da saúde, e que se relaciona com a tutela do participante no processo de investigação e experimentação de terapias inovadoras e ensaios clínicos.

Nos termos da Lei no 21/2014, de 16 de Abril (3), que veio substituir a Lei sobre ensaios clínicos, n 46/2004, de 19 de Agosto, a natureza e a finalidade dos ensaios tem que ser conciliada com a tutela dos direitos e da dignidade dos participantes nos ensaios. A investigação e os ensaios clínicos visam a obtenção de conhecimentos que podem vir a revelar-se úteis, no futuro, para uma generalidade de pessoas, mas não se dirigem à cura ou ao benefício de um doente concreto, como sucede no âmbito da administração de fármacos, ou da realização de intervenções com finalidade curativa. Por isso mesmo, colocam-se a este nível questões específicas, relacionadas com o esclarecimento e a obtenção do consentimento dos participantes nos ensaios, com a sua remuneração, ou possibilidade de remuneração, mesmo indirecta, como sucede nos Estados Unidos, em 
que se praticam verdadeiras formas de aliciamento, prometendo alimentação, entretenimento e alojamento grátis aos intervenientes em certas experiências, com a responsabilidade pelos danos que eventualmente possam ocorrer, com a administração de placebos que não envolvem qualquer possibilidade de benefício individual, mas que podem produzir certo tipo de efeitos psíquicos e físicos, de que as pessoas integradas em grupos de controlo devem ser informadas, entre inúmeras outras questões.

Muito embora se trate de um domínio em que a protecção da dignidade das pessoas, da sua autonomia, e dos seus direitos, é fundamental - será ocioso lembrar as hediondas experiências efectuadas nos campos de concentração nazis, e o nome de Mengele, ou os testes com medicamentos que, já mais perto de nós na história, foram levados a cabo nos países do terceiro mundo por investigadores privados das grandes potências económicas mundiais - entendemos que a discussão em torno da questão da equidade na repartição dos recursos existentes em caso de tratamentos inovadores e particularmente caros, se deixa revestir de maior actualidade e interesse, não só porque se concretiza em decisões e escolhas com consequências dramáticas para os doentes e as suas famílias, mas também porque nelas se jogam equilíbrios valorativos extremamente complexos, que têm escapado, na sua maioria, ao escrutínio dos nossos tribunais, por se entender que as valorações jurídicas pouco têm a dizer sobre elas.

Os direitos invocados pelos doentes neste domínio deixam-se revestir de uma natureza incontornavelmente social, o que os enfraquece, e torna a sua tutela mais débil, uma vez que não se deixam associar a posições subjectivas de conteúdo determinado. (4).

Por outro lado, não estando em causa a apreciação da constitucionalidade de verdadeiros actos normativos, do que se trata é da tutela do particular contra decisões que convocam justificações de natureza política e estratégica, e que mesmo que se enquadrem dentro da categoria do acto administrativo, é duvidoso que não pertençam já a uma reserva insindicável de discricionariedade e de ponderação. Esta questão foi, de resto, colocada e discutida perante os tribunais, a propósito do encerramento de várias salas de parto no país, e no âmbito do processo relativo ao encerramento da Maternidade Alfredo da Costa.

A aquisição e comparticipação de grande parte dos medicamentos e tratamentos inovadores onera fortemente o erário público, e é susceptível de desequilibrar as contas e o orçamento dos hospitais, do SNS, e do próprio Estado. A solução para o problema 
poderia ser a mais radical de todas, ou seja, a sua não introdução no mercado. Na verdade, trata-se de remédios que resultam de anos, e décadas, de investigação, em relação aos quais funcionam lógicas de mercado e de concorrência muito agressivas, e do uso de tecnologia de ponta, pelo que o preço a pagar por doente ronda, muitas vezes, os milhares de euros (medicamentos contra a hepatite C, contra o cancro, contra doenças inflamatórias como a doença de Crohn, contra doenças raras, entre outras).

Não vamos especular sobre a questão de saber se o Estado tem conduzido bem, ou não, a sua relação com as farmacêuticas, e a política do medicamento. Também não vamos aprofundar a polémica que rodeia a prática comercial das farmacêuticas que, muitas vezes, tiram partido da sua posição de exclusividade, ou quase exclusividade, no mercado, para cobrar valores extremamente elevados pelos medicamentos, alegando que passados poucos anos a concorrência, que entretanto também entra no mercado, as vai impedir de praticar esses preços, tendo-Ihes sido muito dispendioso o processo de investigação.

A lógica de Salomão, rei de Israel, levaria a considerar o sacrifício de todos, ou a venda apenas a quem tivesse recursos suficientes, mas essa solução não seria sequer razoável sob o ponto de vista económico, porque obrigaria o Estado a desembolsar somas, também avultadas, no tratamento e acompanhamento destes doentes cujo estado de saúde se iria provavelmente agravar (o tratamento de todos os doentes com hepatite C envolve um custo anual para o Estado de cerca de 71 milhões de euros, dos quais cerca de $80 \%$ dizem respeito às complicações decorrentes da evolução da doença, seja com a realização de transplantes hepáticos, seja com o debelar dos cancros associados à doença).

A outra alternativa, também indefensável, e incomportável sob o ponto de vista das finanças públicas, aponta no sentido da sua disponibilização e comparticipação a todos os utentes. Mas sabemos que o Serviço Nacional de Saúde não consegue sustentar de forma ilimitada o preço dos medicamentos inovadores, sem dúvida eficazes, que muitas doenças requerem (o número de doentes com hepatite $\mathrm{C}$ em Portugal, ronda as 37.000 pessoas, segundo um estudo de 2013, e a previsão relativa ao número de doentes oncológicos também indica uma tendência de aumento, de acordo com dados da DGS - Portugal, doenças oncológicas em número, 2013). No Brasil, onde estes problemas se colocam de forma ainda mais premente, e onde é prática corrente a interferência dos tribunais nas 
decisões da Administração Central e dos hospitais a este nível, chegou-se à conclusão de que o tratamento integral da hepatite $\mathrm{C}$, e da artrite reumatoide pelo Estado, ficaria mais caro do que o funcionamento de todas as estruturas públicas relacionadas com a saúde. Para fornecer gratuitamente os medicamentos para estas duas doenças, que afectam $1 \%$ da população brasileira, o Estado gastaria mais, do que gasta actualmente com a totalidade dos internamentos, diagnósticos, cirurgias, tratamentos, acções de educação para a saúde, vigilância e prevenção sanitária para toda a população.

Num mundo imperfeito, com recursos escassos, impõe-se a sua repartição de forma justa, o que não pode significar o cumprimento de um princípio de igualdade formal, segundo uma regra de equiparação que não olha a fragilidades, necessidades e características específicas, já que se assim fosse, o Estado estaria a garantir medicamentos e cuidados de saúde a quem não precisa, e a descurar os interesses de quem mais precisa, ou dito de outra forma, a desbaratar recursos. O que se pretende é que em cada decisão a tomar, a balança entre o direito à vida e à integridade física de cada um, e o interesse da generalidade, que contempla a saúde de todos, mas que integra também o interesse em ver cumpridas outras funções pelo Estado, funcione de forma equilibrada e justa. E é este o cerne das nossas preocupações. Saber, em primeiro lugar, quais os critérios pelos quais se deve reger um tal equilíbrio e, depois, tendo consciência de que é sempre fácil formular soluções e regras teóricas que não se têm que aplicar na prática, garantir, que uma vez que se trata de decisões extremamente difíceis e passíveis de erro, e que afectam como nenhumas outras os direitos mais importantes das pessoas, se tornam susceptíveis de apreciação pelos tribunais. Os critérios que orientam a decisão de encerramento ou suspensão de um serviço, a recusa de um medicamento ou tratamento a um doente, ou o funcionamento, ou não, de uma estrutura hospitalar, não só devem ser sindicáveis pelos tribunais, no sentido de estes poderem apreciar e valorar a sua compatibilidade com princípios fundamentais do ordenamento, e com direitos constitucional e legalmente consagrados, como devem ser aí apurados e desenvolvidos em sede interpretativa, de forma a poder valer como arrimo de outras decisões. Não nos convence a linha de raciocínio segundo a qual, por estarem em causa decisões complexas, onde se entrecruzam valorações médicas e científicas e opções políticas e financeiras, o direito pouco, ou nada, tem a dizer sobre elas, pelo que deve renunciar ao estabelecimento de critérios, encarando a aleatoriedade, a discricionariedade e a falta de 
objectividade como custos normais e socialmente toleráveis de viver num mundo com recursos limitados, em que o decisor tem que tomar opções políticas.

Muitas decisões relativas à distribuição de recursos na área da saúde assentam em valorações e conhecimentos de natureza médica que não são acessíveis ao julgador. Apenas os médicos estão em condições de determinar qual o grau de sucesso que pode ter uma intervenção ou tratamento, e se a administração de um medicamento inovador é, ou não, medicamente indicado. O julgador não pode tomar decisões acerca da prevenção, diagnóstico, e prognóstico de determinadas doenças, assim como não pode substituir o juízo do médico pelo seu, onde se trata de definir a necessidade do tratamento, ou de averiguar o cumprimento de regras técnicas na sua execução. Além disso, sabe-se da posição defensiva e paternalista que ainda hoje revela a classe médica em relação à apreciação das suas valorações por parte do direito e dos tribunais. Não obstante o esforço que tem sido feito nos últimos anos para garantir a sujeição dos médicos a regras capazes de assegurar a eficácia, a adequação, a razoabilidade e o cuidado das suas decisões, como sucede no âmbito do consentimento informado, ou em relação ao apuramento da violação de deveres de cuidado no domínio da negligência, a verdade é que não só continua a ser difícil para o direito lidar com o uso de uma linguagem técnica hermética e tecnicamente complexa, como continua a ser muito grande o espaço de discricionariedade que é reconhecida à valoração e decisão clínica, acabando em muitos casos, por não se conseguir ir para além da averiguação da razoabilidade da decisão pelo juiz.

Mas muitas decisões que parecem ser exclusivamente médicas, ou ditadas por razões estritamente clínicas, são tomadas em função de pontos de vista económicos e políticos, e isto independentemente de serem médicos, gestores, ou departamentos financeiros, a terem a responsabilidade das mesmas decisões. Um critério estritamente médico, independentemente da falta de transparência que pudesse ter aos olhos do jurista, apenas poderia recomendar o tratamento de todas as doenças e males, utilizando para esse fim todos os meios conhecidos e científica e tecnicamente adequados. Não tendo o médico que curar, ou tratar, apenas um doente, e não dispondo de "todos os meios pensáveis", tem que proceder a escolhas, que lhe são muitas vezes impostas, e que são escolhas de gestão. E essas escolhas têm que ser avaliadas, porque não existe a garantia de que prevalece nelas a preocupação com a vida e a saúde dos doentes, podendo as 
preocupações financeiras sobrepor-se de tal modo à valoração clínica, que ela deixa de ter importância, ou reflectir equilíbrios errados de interesses, não coincidentes com pontos de vista exclusivamente médicos. Embora seja difícil definir ao nível das ponderações feitas, entre o espaço que nelas cabe à valoração e à razão médica, e a critérios de oportunidade e de eficiência, parece-nos que há razões bastantes a justificar a apreciação da legitimidade dos pontos de vista - não médicos - que conduziram até elas. Neste sentido, de forma mais radical ainda, e em face a um ordenamento jurídico completamente distinto, Pieterse M (5):

Se é verdade que os médicos têm que tomar decisões de distribuição de recursos "no momento" baseadas em critérios clínicos de necessidade, também é verdade que essas decisões são muitas vezes condicionadas por critérios não clínicos, impostos por departamentos e agentes administrativos, dentro de um espaço politicamente determinado de recursos disponíveis. Efectivamente, pode sustentar-se que a maioria das decisões de racionamento de recursos, independentemente de quem as toma, são decisões políticas, e não apenas clínicas. Não há por isso razão para não as sujeitar ao mesmo tipo de controlo a que estão sujeitas as decisões de natureza puramente política.

Colocamo-nos assim perante o problema de fundo que rege todas estas considerações. Como se defendem os direitos dos doentes perante uma eventual falta de equidade da decisão que os afecta? Pode o poder judicial interferir legitimamente em opções de oportunidade e adequação sem desrespeitar o princípio da separação de poderes, e o próprio princípio democrático segundo o qual o juiz não pode interferir em áreas de actuação que exigem, nas palavras de Sérvulo Correia (6) "legitimidade democrático-eleitoral directa ou indirecta (e não mera legitimidade institucional)"? Mas mesmo admitindo que não estejam em causa opções integralmente políticas, será que a reserva de valoração e de discricionariedade que a lei reconhece à decisão administrativa (art- 3 , no 1 , do CPTA (7)) Ihe permite escapar à valoração pelo direito, designadamente onde se desafiam princípios jurídicos básicos de ponderação? Será que não é possível antever, na actuação governativa a este nível, como na de gestores e médicos, uma grande medida de implementação da lei e dos seus critérios, logo, o desenvolvimento de uma actividade administrativa integralmente sindicável?

E pergunta-se ainda: sendo o direito à saúde um direito de natureza social, sob reserva do possível, faz sentido permitir ao poder judicial a actualização de juízos de 
"possibilidade" financeira capazes de interferir com direitos de outras pessoas, na área da saúde, ou em outras áreas sociais? Ao admitir a intervenção dos tribunais nesta sede, não estamos a abrir a porta ao fenómeno da judicialização da saúde, e à obtenção de atendimento médico, medicamentos e prestações terapêuticas pela via judicial, que se verifica em países como o Brasil com consequências incontroláveis para o orçamento do Estado?

O direito à saúde constitucionalmente consagrado (art. 64ํ da CRP) (8) é um direito social, pelo que tem um conteúdo essencialmente indeterminado, ou seja, não se torna possível identificar a partir da norma constitucional o alcance e o tipo de pretensões de saúde que o cidadão pode dirigir ao Estado (9), (10), (11), (12).

E mesmo a leitura do ํo 2 desta disposição que estabelece a forma pela qual o direito á saúde é realizado, ou do ํㅡ 3, que consagra as tarefas prioritárias do Estado no domínio da saúde, não dá um grande contributo para o encerramento ou completude normativa deste direito no plano constitucional. O que faz sentido, pois tratando-se o direito á saúde, como outros direitos de natureza social, de direitos cuja realização depende das condições económicas do Estado e do seu grau de desenvolvimento (de direitos sob reserva do possível), o legislador constitucional nunca poderia amarrar o Estado a obrigações e compromissos precisos nestes domínios, remetendo, tal como fez, essa tarefa para o plano infra-constitucional, para o domínio da actuação legislativa ou da intervenção judicial. Não vamos agora discutir, porque pensamos que não é este o local para o fazer, se desse modo estes direitos perdem consistência ou fundamentalidade, ou se mantém a sua natureza jus-fundamental, integrando a norma legislativa o seu conteúdo, e ficando assegurada a sua igualdade hierárquica e valorativa em relação aos designados direitos de liberdade, os direitos, liberdades e garantias, embora adiantemos que esta opinião favorece claramente a nossa linha de raciocínio.

Acerca da situação actual dos direitos sociais, e da ruptura entre o sistema económico e as opções políticas, que enfraquece as possibilidades de prestação do Estado, e o modelo ocidental que inspirou a estruturação da nossa ordem constitucional (13).

Do que não pode haver dúvida é de que não é possível ter acesso ao conteúdo do direito fundamental à saúde através da leitura do texto constitucional, pelo que o juízo acerca da legitimidade das decisões da Administração que neste domínio afectam direitos 
e posições jurídicas dos particulares, terá que ser feito em face da intervenção conformadora, concretizadora e densificadora do legislador ordinário, e das dotações orçamentais também elas legislativamente previstas para este domínio de actividade. 0 conteúdo do direito fundamental decorre do encontro entre a norma aberta que na Constituição consagra o direito à saúde, e o conjunto das normas infra-constitucionais que estabelecem direitos a prestações derivados. Ao nível da Constituição, e não nos referimos aqui de forma detalhada a todos os diplomas e declarações internacionais que vinculam 0 Estado português à tutela da saúde dos seus cidadãos, porque pressupomos que eles se reflectem, e têm expressão, na ordem jurídica interna, consagra-se a opção fundamental da tutela do direito, afirma-se a essencialidade da saúde para os cidadãos e para a colectividade, conferindo-se depois consistência a este direito através da intervenção do legislador ordinário que, neste domínio, se faz a vários níveis.

Destaca-se aqui a Lei de Bases da saúde (14), a Lei que veio instituir o Serviço Nacional de Saúde (15), a Lei que aprova o Estatuto do Serviço Nacional de Saúde (16), a Lei que consolida a legislação em sede de tutela dos direitos e deveres dos utentes dos serviços de saúde (17), a Lei que consagra medidas para a racionalização da política do medicamento no âmbito do serviço nacional de saúde (18), entre tantos outros diplomas.

A evolução que sofreu, entre nós, o sistema nacional de saúde, constitui um bom exemplo de como a realidade ao nível das prestações do Estado no domínio da saúde se tem que adaptar aos recursos existentes. O serviço nacional de saúde, que representou uma conquista fundamental dos cidadãos, foi criado no início da década de noventa, com a aprovação da lei de bases de saúde, e com o Estatuto do serviço nacional de saúde em 1993 (19). Este serviço, que se desdobra em múltiplas prestações, garante a equidade na saúde através do acesso de todos os cidadãos, independentemente das suas condições económicas, a cuidados de medicina curativa e preventiva, bem como a cobertura médica e hospitalar do país, da forma mais racional e eficiente possível, através do recurso a fundos públicos.

A complexidade do sistema de saúde, e a multiplicidade de prestações em que se desdobra, torna particularmente difícil a questão da gestão de recursos e a realização de opções no plano político, uma vez que a "promoção da saúde e a prevenção da doença" de que fala a Base II, da Lei de Bases da Saúde (20)), abrange a prevenção e o combate à doença, a assistência medicamentosa, a prevenção da toxicodependência, os cuidados 
pré-natais e pediátricos, os cuidados paliativos, a investigação na área da saúde, estendese a domínios que tradicionalmente já pertencem á área da segurança social, ou do bem estar social, e vai porventura ainda mais longe, se adoptarmos a concepção ampla de saúde da OMS, que inclui neste conceito, não só o acesso aos cuidados de saúde, como as condições de vida capazes de evitar a doença, e a eliminação das desigualdades no acesso aos cuidados de saúde. Ao definir a saúde como "um estado de completo bemestar físico, mental e social, e não somente ausência de doenças e enfermidades", a OMS inclui neste conceito a própria eliminação das desigualdades de género, ou seja, a adopção de medidas concretas ao nível da educação, da formação profissional, e mesmo no plano eleitoral, capaz de promover o desenvolvimento global da pessoa (21).

No entanto, em vinte anos, a realidade do país mudou. Aumentou a complexidade dos cuidados de saúde prestados, quer sob o ponto de vista da assistência medicamentosa, quer ao nível dos equipamentos e da articulação entre os profissionais de saúde, aumentaram em conformidade os custos de funcionamento de toda a máquina de prestação de serviços, modificou-se profundamente a relação entre o médico e o doente que se tornou muito mais exigente e se despersonalizou, aumentou a esperança de vida da população (em 1974 era de 68 anos, em 2014 de 80 anos, embora com diferenças para homens e mulheres) e os problemas associados ao seu envelhecimento, e assistiu-se à empresarialização dos serviços hospitalares, passando a redução dos custos e a gestão de meios a ter aí uma importância fundamental. Já num contexto de crise económica, e perante a dificuldade de distribuir os recursos existentes face a um sistema de saúde cada vez mais dispendioso, foram introduzidas e atualizadas as taxas moderadoras como forma de racionalizar a procura e foram sendo reestruturados os próprios serviços.

Identificado o quadro normativo em que se integra o direito à saúde, onde se reconhece expressamente que têm que ser feitas ponderações de vária ordem, para adaptar os recursos financeiros do Estado às necessidades sentidas pela população (não faz sentido consagrar legislativamente formas de realização do direito que excedam os recursos financeiros do Estado, ou que comprometam a realização de outras tarefas fundamentais do Estado), salvaguardando sempre o mínimo essencial do direito que terá que se manter imune a exigências de ordem orçamental e económica, e que se relaciona com a garantia da dignidade da pessoa humana (não se pode adoptar uma política de saúde que condene pessoas à morte porque não estão em condições de pagar os 
cuidados básicos de saúde, tendo o Estado que assegurar o acesso à rede de saúde primária, programas de vacinação e medicamentos essenciais, de acordo com a OMS), caracterizada a realidade do nosso país e a complexidade e diversidade das prestações de saúde asseguradas pelo Estado, chegamos ao plano das decisões concretas da administração e dos hospitais.

A Base 1, n.2, da Lei de Bases da Saúde, estabelece o seguinte: "O Estado promove e garante o acesso de todos os cidadãos aos cuidados de saúde nos limites dos recursos humanos, técnicos e financeiros disponíveis", e a Base 2, $n^{\circ} 1$, alínea b), afirma que: "é objectivo fundamental obter a igualdade dos cidadãos no acesso aos cuidados de saúde, seja qual for a sua condição económica e onde quer que vivam, bem como garantir a equidade na distribuição de recursos e na utilização de serviços, ressalvando a alínea c), a necessidade de tomar medidas especiais de protecção em relação a grupos particularmente vulneráveis como os toxicodependentes, as crianças e os idosos. Por sua vez, o Decreto-Lei no 106-A/2010, relativo à política do medicamento, e que é um dos instrumentos que procura introduzir equilíbrio no sistema, garantindo a sustentabilidade do SNS, não deixa de referir o seu Preambulo, preocupações de equidade.

Confrontamo-nos aqui com a dificuldade em distinguir a decisão administrativa da decisão política, tendo presente um conceito de decisão política em sentido lato, que se coloca fora dos poderes de sindicabilidade dos tribunais administrativos.

Falamos em decisão política em sentido lato, de forma a abranger, não apenas os actos correspondentes ao exercício da função política (actos políticos em sentido estrito), e que exprimem opções fundamentais sobre a definição e a realização dos interesses gerais da colectividade, mas também os actos praticados no âmbito da função administrativa não regulados por normas ou princípios jurídicos ( $n^{\circ} 1$, do art. $3^{\circ}$, do CPTA), e que são apenas os actos de autoridade cuja não sindicabilidade é cada vez mais contestada, uma vez que todos os restantes actos e decisões administrativas terão que estar sujeitos à apreciação dos tribunais administrativos por imposição constitucional - art. $22^{\circ}$ da CRP.

De acordo com o Acórdão do Supremo Tribunal Administrativo, de 3 de Junho de 2007, n 01143/06, a função política que "corresponde à prática de actos que exprimem opções fundamentais sobre a definição e a prossecução dos interesses ou fins essenciais da colectividade", integra-se conjuntamente com a função administrativa, essa sim sujeita à apreciação jurisdicional, no âmbito da actividade do poder executivo. Esta função política, 
que é muitas vezes exercida através de decreto-lei orientando a actividade administrativa, não constitui actividade executiva em sentido estrito, uma vez que não se limita à execução de leis já existentes, embora também não se confunda com a actividade legislativa, uma vez que não traduz uma intervenção inovadora.

$\mathrm{Na}$ medida em que grande parte das decisões do Governo e da Administração que envolvem opções de distribuição de recursos na área da saúde envolvem uma grande margem de liberdade e de apreciação, porventura maior do que a que caracteriza a discricionariedade que assiste a estes órgãos no exercício da função administrativa, poderíamos ser tentados a qualificá-las como decisões políticas, o que não nos parece o mais correcto, uma vez que não só não está em causa uma mera definição de estratégias, ou da melhor forma de realizar os interesses fundamentais da colectividade (não podemos admitir que se caracterize como livre, ou como meramente política, a actividade de definição de critérios para o acesso a medicamentos, ou intervenções médicas, tendo em conta os direitos que estão em causa, e sendo certo que é uma área de actividade densamente regulada), como, por outro lado, estamos longe de nos encontrar num domínio juridicamente livre como aquele que se faz corresponder ao exercício da discricionariedade política.

Podemos então entender que estamos, na maior parte dos casos, perante formas de actuação de índole ou natureza administrativa, sujeita à lei, e embora sendo verdade que mesmo no domínio da decisão administrativa é reconhecida à Administração uma "reserva política" que corresponde ao juízo de conveniência e oportunidade das escolhas feitas (art. $3^{\circ}, n^{\circ}$ 1, do CPTA), parece-nos que a maioria das decisões tomadas no domínio da saúde, e as ponderações que as fundamentam, têm que estar de acordo com normas e princípios jurídicos, não podendo ser invocada a liberdade de decisão como razão de impedimento da intervenção do tribunal. Como afirmou o Supremo Tribunal Administrativo no Acórdão já referido, de 3 de Junho, de 2007, "os poderes de cognição dos tribunais administrativos abrangem apenas as vinculações da Administração por normas e princípios jurídicos, e não a conveniência ou oportunidade da sua actuação (...) pelo menos quando não se detectar concomitantemente a ofensa de princípios jurídicos".

Quais são então os critérios, ou as valorações jurídicas, cujo cumprimento caberá ao juiz verificar relativamente à decisão administrativa ou de gestão concreta tomada no 
domínio da saúde, tendo como certo que essa decisão não se pode legitimar com base em critérios vagos de equidade, clínicos, ou financeiros?

Não faltam tentativas de resposta para a questão da equidade, e para a sua definição. Encontramos assim as teorias utilitaristas, a teoria da justiça de Rawls, a teoria de propriedade de Locke, e muitas outras, que não vamos elencar aqui. Fundamentalmente, há que ter presente que o que é igual, deve ser tratado de forma igual, e que a diferença de posições deve merecer atenção quando se quer atingir a igualdade. Não nos parece que o critério a adoptar para dar conteúdo a esta regra de equidade ou de parificação, de tratamento justo, se quisermos, possa ter uma natureza estritamente económica, embora, onde se fala de recursos, essa dimensão tenha que estar inevitavelmente presente (seria o caso se o Estado decidisse comparticipar um determinado medicamento a todos os doentes até um determinado limite ou montante, independentemente da sua situação concreta). A ideia do tratamento desigual como forma de obter a igualdade, é a que preside, ou inspira - embora suscitando reservas sob o ponto de vista fiscal, por exemplo, em relação aos que mais contribuem, e que, por conseguinte, entendem que também deveriam ser contemplados pelas prestações do Estado em igualdade de circunstâncias em relação aos que têm menos recursos - o funcionamento das taxas moderadoras, e a imposição de limites à comparticipação de medicamentos, atendendo à situação financeira e patrimonial concreta do utente. A equidade na saúde significa aqui igual oportunidade para ser saudável em todos os grupos da população, o que impõe que os recursos na saúde sejam distribuídos de forma a permitir aos mais desfavorecidos aproximar-se dos mais favorecidos, utilizando a prestação de cuidados de saúde como um instrumento de justiça social

Vimos que o direito da saúde se deixa conformar através da Constituição e de opções legais de natureza infra-constitucional, pelo que só poderá ser considerada legal/constitucional/legitima a decisão que respeite em primeiro lugar, as opções do legislador ordinário nesta matéria, e os critérios de ponderação que orientam a formulação da lei na concretização do direito em causa, e que não podem deixar de ser critérios de natureza constitucional. Seguimos aqui uma perspectiva unitária dos direitos fundamentais, tal como a que sustenta entre nós Reis Novais $J$ (22), e parece não ser rejeitada por Medeiros R (13). 
Como a nossa Constituição estrutura a sociedade portuguesa em moldes valorativos bem definidos, não haverá dúvidas de que qualquer distribuição de recursos que tenha lugar não pode comprometer a dignidade essencial da pessoa, que neste domínio está directamente relacionada com a protecção da vida e da integridade física, que não são direitos sujeitos à reserva do possível, e cuja restrição depende da reunião dos

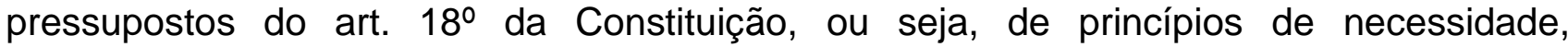
proporcionalidade e mínima restrição possível.

Não desconhecemos que o nosso Tribunal Constitucional tem optado, onde se discute a afectação de direitos sociais, por uma linha de argumentação mais principialista, do que baseada na restrição de direitos, o que parece uma consequência lógica da diferente densidade e natureza destes direitos quando postos em confronto com os direitos, liberdades e garantias. Todavia, se entendermos que a valoração constitucional informa a legislação ordinária, e que esta se mostra de acordo com o parâmetro normativo fundamental, qualquer diminuição ou comprometimento do conteúdo da lei e das garantias constitucionais com reflexo nos direitos das pessoas, constituirá uma restrição de direitos fundamentais (fiscalizável em sede de constitucionalidade se se tratar de actos legislativos), e uma afectação de posições jurídicas individuais que poderá ser apreciada segundo esses mesmos princípios, se estiver em causa uma actuação administrativa.

Por outro lado, têm que ser tidos em conta, como partes integrantes do conceito de bem comum constitucionalmente consagrado, valores de igualdade, justiça, liberdade e solidariedade, o que pode justificar, como acabámos de ver, a colocação de recursos ao serviço de necessidades urgentes e vitais de camadas mais desfavorecidas ou vulneráveis da população, como forma de eliminar desequilíbrios, e garantir a igualdade e liberdade de todos.

Estando em causa a vida e a integridade física das pessoas, o critério determinante da oportunidade ou conveniência de uma medida, deve ser um critério de natureza médica, relacionado com a existência de um interesse ou finalidade curativa do medicamento ou intervenção, e com o diagnóstico e a evolução previsível da doença e taxas de mortalidade.

Tratando-se de medicamentos, os serviços de saúde devem actuar em conjunto com a entidade reguladora do medicamento, articulando exigências terapêuticas (se 0 medicamente é eficaz, se é inovador, se a sua introdução não traduz uma multiplicação de 
medicamentos para o mesmo fim, se não se trata de um medicamento de resultado não comprovado ou que apresenta escassa vantagem em relação aos já existentes) e de racionalidade, antes de decidir introduzir os medicamentos no mercado, e a sua comparticipação e acesso deve depender da avaliação do interesse terapêutico no caso concreto. Em certos casos, antes da aprovação do medicamento, podem ser autorizados pedidos de natureza excepcional.

Um hospital sul-africano, excluiu um doente do acesso aos serviços de diálise porque entendeu que ele não cumpria os requisitos de elegibilidade para o tratamento (24), tendo o doente invocado perante os tribunais o direito à vida e o direito a tratamento médico de emergência. $O$ caso foi o seguinte: um doente que precisava de fazer diálise para prolongar a vida, não dispondo de meios para o fazer no sector privado de saúde, solicitou a sua realização num hospital do Estado. Infelizmente este hospital não podia garantir a realização da diálise a todos os doentes que a precisavam de fazer, e como a diálise não "cura", mas apenas permite prolongar a vida, e o doente não era elegível para transplante de rim, foi excluído de acordo com os critérios de admissibilidade do hospital. O tribunal entendeu que não tinha sido posto em causa o direito à saúde porque este não se deixa deduzir do direito á vida, nem do direito a tratamento de emergência, e considerou que estavam em causa critérios clínicos de repartição de meios escassos entre doentes que não podia valorar, sendo certo que o critério que foi utilizado encontrava a sua justificação no corte de recursos que foi considerado necessário na unidade de diálise renal do hospital que foi imposto na sequência da redução orçamental do hospital e do departamento de saúde da província em causa. Uma vez que os critérios de admissibilidade para a realização de diálise no hospital tinham por objectivo maximizar o acesso efectivo ao tratamento disponível, e uma vez que o autor da acção não sugeriu que estes critérios fossem irrazoáveis, ou aplicados de forma desrazoável ou injusta, eles foram considerados constitucionais.

Neste caso, que se poderia colocar em face da nossa ordem jurídica, embora ressalvando que à luz do nosso ordenamento, e de acordo com o art. 150 do Código Penal $(25)^{2}$, a diálise constitui uma intervenção curativa, uma vez que se trata de um meio

\footnotetext{
${ }^{2}$ Art. 150ํㅡㄴ ํㅜ 1 (Intervenções e tratamentos médico-cirúrgicos): As intervenções e tratamentos que, segundo o estado dos conhecimentos e a experiência da medicina, se mostrarem indicados e forem levados a cabo, de acordo com as leges artis, por um médico ou por outra pessoa legalmente autorizada, com intenção de
} 
indicado para debelar doença ou sofrimento, de acordo com um sentido amplo de cura coincidente com a melhoria do estado geral da pessoa ou do doente, estamos perante uma evidente interpenetração de critérios médicos e de gestão, que poderia justificar a mesma conclusão de insindicabilidade por parte dos tribunais. No entanto, parece-nos que os tribunais não podem - ou não devem - assumir, que pese embora a existência de espaços óbvios de valoração por parte das entidades de saúde, as suas decisões são sempre razoáveis e tomadas de boa fé, com a justificação de que nesta área todas as decisões são difíceis de tomar, e de que os recursos não são inesgotáveis, uma vez que essa linha de argumentação inviabiliza a pretensão de realização de qualquer direito social. Não só a falta de recursos carece de demonstração, não constituindo um facto natural ou óbvio, como devem ser ponderados os argumentos e razões em presença, em face da lei, e dos princípios fundamentais do ordenamento.

Supondo que um critério de utilidade médica e terapêutica torna indicado o tratamento, o que fazer quando a recusa do medicamento, ou da intervenção, significa que ficam doentes por tratar? Numa primeira aproximação, diríamos que a recusa de um tratamento que compromete bens jurídicos essenciais não é legítima, uma vez que o direito à vida não ser ponderado no âmbito do art. $18^{\circ}$ que estabelece os limites de legitimidade da restrição dos direitos, liberdades e garantias. No entanto, não se pode perder de vista que não está aqui em causa a afectação directa do direito à vida, ou à integridade física de uma pessoa, mas da realização de um direito que é de todos, e que é garantido através de recursos ou meios que pertencem a todos, o direito à saúde. Sendo assim, a questão será esta: faz sentido paralisar o serviço nacional de saúde custeando um só tratamento de milhões de euros? Pode negar-se o direito à saúde de milhares de pessoas para satisfazer a necessidade vital de um medicamento de um só membro da sociedade, sendo certo ainda que a decisão terá que ser tomada de forma geral, ponderando a possibilidade de ter que fornecer o mesmo tratamento a mais doentes em número potencialmente indeterminado? Este é, sem dúvida, um dilema ético, mais do que jurídico, tal como aqueles que no direito penal se integram no âmbito do estado de necessidade desculpante, a exigir o funcionamento de uma ideia de razoabilidade e de

prevenir, diagnosticar, debelar ou minorar doença, sofrimento, lesão ou fadiga corporal, ou perturbação mental, não se consideram ofensa á integridade física. 
exigibilidade. A assistência na saúde que garante o Serviço Nacional de Saúde (SNS) deve ser assegurada a todas as pessoas que procurem diagnóstico e tratamento nos estabelecimentos de saúde pública, mas de acordo com as regras estabelecidas pelo próprio SNS com a preocupação de garantir os direitos de todos. Tenha-se inclusivamente presente a ideia que orienta a lei da responsabilidade civil extracontratual do Estado (26), que prescreve no seu art. $7^{\circ}, n^{\circ} 4$, que apenas existe responsabilidade pelo funcionamento anormal do serviço onde a "atender a circunstâncias e a padrões médios de resultado, fosse razoavelmente exigível ao serviço uma actuação susceptível de evitar os danos produzidos". O direito à saúde não pode ficar sem conteúdo relativamente a todos os restantes cidadãos, pelo que a realização do direito de uma pessoa, ou de um grupo de pessoas, não pode traduzir o esvaziamento completo do conteúdo desse direito em relação á generalidade, sob pena de se estar a desrespeitar o princípio da igualdade, da proporcionalidade, e o mínimo ético essencial do direito.

Pode haver casos, todavia, em que a comparticipação de um medicamento ou a realização de uma intervenção, não compromete a sobrevivência do serviço nacional de saúde, e o princípio da igualdade de tratamento dos utentes, revestindo-se de caracter ou natureza excepcional ${ }^{3}$. Onde não existe alternativa, e estando em causa a vida de uma pessoa, o argumento da "reserva do possível" deve ser utilizado com moderação, não parecendo justificar a natureza pontual do encargo a utilização de argumentos como a eventual não realização do interesse público noutros domínios como a habitação, a educação ou a defesa (embora, e mais uma vez, se tenha que averiguar do equilíbrio da decisões em face das circunstâncias do caso concreto).

O que aqui dizemos não invalida o reconhecimento de que o crescimento das necessidades individuais e colectivas neste domínio tem vindo a superar em muito a capacidade de crescimento das disponibilidades financeiras do Estado. A crise financeira sentida a nível mundial, conjugada com o aumento da esperança de vida na maior parte dos países ocidentais, e o preço dos medicamentos e de outros dispositivos necessários para a manutenção da saúde das pessoas, tem conduzido a uma rápida e progressiva

\footnotetext{
${ }^{3}$ Acerca da autorização excepcional da aquisição de fármacos pelos hospitais do Serviço Nacional de Saúde, veja-se o Decreto-Lei n.. 97/2015, de 1 de junho, o Decreto-Lei n.. 176/2006, de 30 de agosto, Regime jurídico dos medicamentos de uso humano, actualizado pela Lei oㅗ 51/2014, de 25 de agosto, e a Deliberação do Infarmed n. $.76 / C A / 2015$, de 18 de junho de 2015, a tornar clara a natureza pontual e limitada de certas autorizações de venda e utilização de medicamentos.
} 
erosão dos meios financeiros disponíveis na área da saúde, ao mesmo tempo que provoca o desequilíbrio ao nível da distribuição de recursos pelos vários sectores de intervenção do Estado. Acerca da progressão deste fenómeno nos Estados Unidos da América, e advertindo para a necessidade de repensar as prioridades ao nível dos cuidados de saúde prestados aos cidadãos (27).

Parece ter sido este o sentido da decisão tomada recentemente pelo Infarmed, e pelo Ministério da Saúde, relativamente ao tratamento da hepatite $\mathrm{C}$, embora tenha sido acompanhada de esforços para a redução do preço do medicamento e pelo estabelecimento de prioridades de tratamento $^{4}$. Se o excepcional a certa altura se multiplica, desdobrando-se em muitos casos excepcionais, então a resposta mais razoável, a única resposta, de acordo com a linha de raciocínio que ficou exposta atrás, parece ser a de abrir mão da justificação da autorização excepcional, porque já não consentida pelo princípio da igualdade que coloca outros com as mesmas necessidades em situação de diferença, fazendo funcionar a "reserva do possível" em face de outros direitos e interesses conflitantes.

Quando milhões de doentes recebem um cuidado do tipo "o custo não é assunto", o resultado é a tragédia económica colectiva. A medicina heroica produz um gasto aterrador. A economia não consegue suportar uma forma de alocação de recursos com vista tão curta. Porque a medicina extraordinária é uma realidade dramática e fortemente publicitada, esquecemo-nos das pessoas e dos programas de saúde que têm que ser sacrificados para a sustentar. Por exemplo, a Califórnia eliminou 250.000 pessoas do Medicaid porque o programa se estava a tornar excessivamente caro. Uma razão para a eliminação do programa foi a decisão legislativa - tomada na mesma sessão - de pagar os transplantes de órgãos. Na verdade, o que fez o legislador foi cortar nos cuidados pré natais e pediátricos para custear transplantes de órgãos o que não é uma forma socialmente responsável de decidir (27)

Não nos aproximamos, por isso, da linha de pensamento que é seguida pelos tribunais brasileiros que, em face de acções movidas por cidadãos concretos contra os poderes públicos, e orientados pelos melhores sentimentos, ordenam a administração de

\footnotetext{
${ }^{4}$ Por vezes, recorre-se, nestas situações, ao tratamento do doente através da sua participação em ensaios clínicos, o que podendo ter inegáveis vantagens para o doente e para o sistema de saúde, não é exactamente o mesmo que ver garantido um tratamento já comprovado e medicamente indicado.
} 
medicamentos não incluídos na política nacional de fornecimento de fármacos, afectando em termos de equidade os direitos de outros utentes que são irremediavelmente prejudicados por falta de meios. Parte-se nestas decisões da ideia de que o direito à saúde é um direito a atendimento e medicação ilimitado, ou seja, que não funciona em relação a ele a "reserva do possível" já que ela colide com o conteúdo mínimo de realização do direito, e que determinante é a ponderação das necessidades concretas do doente, quando nos parece que a recusa da administração de um medicamento não pode ser vista como sinónimo de violação do direito à saúde. Por outro lado, estas decisões contrariam o entendimento de equidade na saúde que é defendido pela OMS, e que já referimos atrás. Segundo esta organização internacional, a igualdade na saúde não é apenas a igualdade de acesso aos recursos e meios que permitem manter a saúde, mas inclui também a necessidade de eliminar a desigualdade social e económica que é capaz de gerar desigualdades no acesso aos cuidados de saúde (por exemplo, a educação e a promoção da igualdade de género é considerada uma das mais eficazes estratégias de promoção da saúde nos países em desenvolvimento). Ora, a possibilidade de recorrer aos tribunais e de propor acções contra o Estado só é possível às pessoas com mais recursos, pelo que a decisão judicial que lhes confere o direito a um determinado medicamento sacrifica duplamente aqueles que já têm piores condições de vida e de saúde e que assim perdem a possibilidade de acesso a programas de vacinação, de educação para a saúde, de prevenção, entre outras dimensões deste direito. Além de que, nos parece erróneo e violador do princípio da separação de poderes, a possibilidade de impor ao Estado uma decisão tomada pelos tribunais no uso de poderes "administrativos" que evidentemente não lhes pertencem.

A valoração das decisões de racionamento de recursos no domínio da saúde, terá que ser feita tendo sempre presente as circunstâncias concretas que as justificam, uma vez que haverá situações em que existem alternativas aos medicamentos e aos tratamentos mais caros e mais recentes, que há casos em que a vida da pessoa se encontra directamente mais ameaçada do que outros, e em que a indicação médica para o tratamento é maior ou menor. Noutro plano, ter-se-á que averiguar da sua compatibilidade com o princípio da dignidade humana, da proximidade da realização do direito social em causa ao cerne dos direitos individuais da pessoa, do cumprimento do princípio da igualdade e do art. $13^{\circ}$ da CRP (ter-se-á que averiguar se para necessidades iguais se 
está a assegurar o mesmo tratamento), e da observância do princípio da proporção ou da proibição do excesso que, em qualquer Estado de direito, vincula a actuação dos poderes públicos.

Ao nível da saúde, e das decisões de racionamento de recursos, adquire uma importância fundamental o cumprimento de um princípio de igualdade que foi considerado pelo TCA, no seu Acórdão de 9 Maio de 2002, um limite interno à prática de actos discricionários, ao estabelecer que "o princípio da igualdade constitui um dos limites internos dos atos praticados no exercício de poderes discricionários. Daí que a sua invocação só assuma relevo quando a Administração atua com liberdade para escolher o comportamento a adotar e não opera no exercício de poderes vinculados, na base de critérios de estrita legalidade".

Terá que existir, em suma, uma relação adequada entre meios e fins, não podendo os decisores tomar medidas excessivas e desequilibradas tendo em conta que de um lado da balança se encontram finalidades de ordem orçamental e económica, a racionalização dos meios e do funcionamento dos organismos e das estruturas e a um nível mais amplo a satisfação de interesses menos próximos de bens essenciais, e do outro lado, direitos de natureza pessoal fundamental. Como se pode ler no Acórdão do Tribunal Constitucional no 187/2001, em desenvolvimento do Acórdão n 634/93: "O princípio da proporcionalidade desdobra-se em três subprincípios: princípio da adequação (as medidas restritivas de direitos, liberdades e garantias devem revelar-se como um meio para a prossecução dos fins visados, com salvaguarda de outros direitos ou bens constitucionalmente protegidos); princípio da exigibilidade (essas medidas restritivas têm que ser exigidas para alcançar os fins em vista, por o legislador não dispor de outros meios menos restritivos para alcançar o mesmo desiderato), princípio da justa medida ou proporcionalidade em sentido estrito (não poderão adoptar-se medidas excessivas, desproporcionadas para alcançar os fins pretendidos). No mesmo Acórdão refere-se a ordem pela qual estes princípios deverão ser avaliados pelo julgador quando colocado face a uma medida restritiva de direitos. Esta ordem ou sequência deverá iniciar-se com a utilização do critério mais amplo ou abstracto que é o da adequação, ou seja, o juízo acerca da idoneidade ou aptidão do meio para a realização do objectivo em vista, seguindo-se depois logicamente a avaliação da exigibilidade da restrição. A restrição só será legítima se constituir, no caso concreto, o meio mais benigno de realização do interesse público, se for o meio menos restritivo e 
menos oneroso, ou seja, se não existirem alternativas que deixem maior espaço de realização dos direitos dos particulares. Finalmente, será de avaliar o cumprimento do princípio da proporcionalidade em sentido estrito, ou seja, se o peso específico de ganho para o interesse público se encontra numa relação equilibrada e proporcional face á carga coactiva ou à medida de sacrifício a que é sujeito o interesse do particular.

Em primeiro lugar, ter-se-á que determinar se se trata, ou não, de uma medida restritiva do direito à saúde, tendo em conta as advertências que já fizemos acerca de decisões que procuram camuflar a sua natureza condicionadora atrás de justificações médicas ou organizatórias, invocando muitas vezes como fundamento decisório a realização do próprio direito á saúde, ou o interesse de grupos de utentes. Uma vez identificada a natureza restritiva da medida, ter-se-á que avaliar se a recusa do tratamento ou do meio medicamentoso em questão, a suspensão de serviços, ou o condicionamento do acesso a determinadas regalias, é adequada a obter o benefício para o interesse público que é invocado como fundamento da recusa (juízo de adequação), se é possível obter o mesmo ganho orçamental ou funcional, através da implementação de outras medidas que não a que é proposta (juízo de necessidade) e, finalmente, se existe proporcionalidade em sentido estrito, isto é, se esse beneficio que se pretender realizar a nível geral, ou sectorial, justifica efectivamente a restrição. O que permite, ao que pensamos, tendo em conta que se trata de um juízo global, ponderar a importância de que se reveste o serviço a prestar ao nível da saúde, em face de outros serviços, ou sectores, do Estado, que se pretendem beneficiar, os incómodos e as perturbações decorrentes para a população da supressão, ou do funcionamento noutros moldes de um determinado apoio ou cuidado, assim como afastar a legitimidade de cortes que sirvam apenas para garantir poupanças irrisórias ou insignificantes ao erário público.

Parece-nos interessante, a esta luz, a posição do Tribunal Constitucional da África do Sul que resolveu substituir todos estes parâmetros em que se desdobra o juízo acerca da legitimidade da restrição de direitos sociais, por um único critério de razoabilidade, com base na exigência constitucionalmente fundada de que as medidas adoptadas para a realização progressiva dos direitos sociais devem ser razoáveis. Este critério de razoabilidade foi utilizado pelo mesmo Tribunal em relação à definição de conteúdo e à implementação da política pública de habitação no caso Grootboom, e impõe que as medidas sócio económicas a adoptar sejam equilibradas, coerentes, flexíveis, inclusivas, 
não discriminatórias e tenham em conta as necessidades urgentes dos sectores mais vulneráveis da sociedade. Num outro caso, Tac, o Tribunal Constitucional considerou que a restrição da administração de uma determinada droga usada para o tratamento do HIV- 1 e Sida, e considerada medicamento essencial pela OMS, a Nevirapine, aos centros de investigação e ensino (mesmo quando a capacidade para administrar, sendo medicamente indicada, existia em muitos outros sítios), era desrazoável e, por conseguinte, inconstitucional. De acordo com Pieterse $\mathrm{M}$, que se mostra particularmente critico da dificuldade demonstrada pelos tribunais em apreciar, sob o ponto de vista jurídico e constitucional, os fundamentos da decisão política, alegando que se trata de uma forma de decisão insindicável, e irracional, o uso deste critério da razoabilidade mostra-se particularmente adequado a ajuizar do acerto de decisões orçamentais e financeiras neste domínio, porque não obriga o juiz a imiscuir-se em domínios que não controla. Pieterse $M$ (5) transcreve criticamente parte de uma sentença proferida em sede de recurso pelo British Court of Appeal, no caso R. v. Cambridge Health Authority, ex parte B, que reflecte, quanto a ele, esta forma de pensar dos tribunais:

Não há dúvidas de que, num mundo perfeito, qualquer tratamento que fosse procurado por um doente, ou pela família de um doente, e indicado pelos médicos, seria garantido, independentemente do seu custo, especialmente estando em causa a vida de uma pessoa. Estar-se-ia, todavia, a fechar os olhos à realidade, se fosse permitido ao tribunal actuar como se se vivesse nesse mundo. É do conhecimento comum que as autoridades de saúde, quaisquer que sejam, estão permanentemente a tentar equilibrar os seus orçamentos: não podem pagar ao pessoal de enfermagem tanto quanto desejariam; não podem comprar todo o tipo de equipamento médico caro que pretendem; não podem desenvolver toda a investigação que gostariam; não podem construir todos os hospitais e unidades especializadas de saúde que lhes apetece. Têm que ser tomadas decisões difíceis e angustiantes acerca da melhor forma de distribuir um orçamento limitado para retirar dele a maior vantagem possível para o maior número de doentes. Esse juízo não pode caber a um tribunal". A partir do reconhecimento de que os hospitais e a administração da saúde têm que tomar decisões angustiantes e difíceis, e que tem que lhes ser reconhecida a liberdade de resolver estes conflitos, o tribunal entendeu que se trata de decisões não valoráveis judicialmente e, por conseguinte, não sindicáveis.

No entanto, um critério genérico de razoabilidade não pode substituir o funcionamento dos critérios constitucionais, até porque não permite ter presente a especificidade do direito à saúde enquanto direito social. Utilizar um critério desta natureza, equivaleria a permitir aos tribunais julgar de acordo com princípios genéricos de equidade, 
legitimá-los a valorar "politicamente" decisões políticas, substituindo o seu juízo de oportunidade ao juízo dos órgãos da administração, com evidente violação do princípio da separação de poderes, quando, o que se pretende é a julgamento dessas decisões segundo princípios de natureza jurídica. Nesse sentido, acompanhamos plenamente a posição sustentada entre nós pelo Supremo Tribunal Administrativo que, a propósito do encerramento de várias salas de parto no país pelo Governo, afirmou que a valoração das decisões administrativas apenas pode ser feita com base em normas e princípios jurídicos, embora nos fiquem algumas dúvidas acerca da qualificação desta decisão de encerramento como decisão tomada ao abrigo de uma reserva política ou de discricionariedade da administração, na medida em que a área da saúde é pouco compatível com a não sindicabilidade quase integral das decisões (a não ser onde se trate de decisões de menor importância, não susceptíveis de atingir o direito social em causa, e os direitos individuais a ele associados).

Efectivamente, os nossos tribunais têm entendido, de forma ainda mais restritiva, que estando em causa o uso de poderes discricionários pela Administração, a sua intervenção fica condicionada à apreciação de aspectos vinculados, como a competência, a forma, os pressupostos de facto e a adequação do processo, ou seja, ao apuramento de situações erro de facto, erro manifesto de apreciação, desvio de poder e incompetência.

Embora o Tribunal, no mesmo Acórdão, tenha admitido que quer as decisões políticas, quer as decisões tomadas segundo regras técnicas ou juízos de adequação pela Administração, têm que estar de acordo com princípios jurídicos fundamentais (que são essencialmente aqueles que referimos como sendo os que, na nossa opinião, permitem ajuizar da conformidade normativa entre estas decisões e o ordenamento jurídico nesta matéria), também considerou ser de restringir o conhecimento do tribunal acerca da violação desses princípios às hipóteses e situações em que ela resulta de forma crassa e evidente das circunstâncias do caso. Relativamente à decisão do Ministro da Saúde em apreço, o Tribunal entendeu que não podia avaliar sob o ponto de vista jurídico o argumento segundo o qual o encerramento das unidades em causa era adequado à redução da mortalidade infantil, ou o de que é conveniente assegurar um ritmo de trabalho não inferior a 1500 partos anuais, para garantir a actualização e o adestramento adequados do pessoal, alegando que não estava em causa uma violação segura e 
positiva, vale dizer, crassa, ou evidente, dos princípios jurídicos da igualdade, da proporcionalidade, da justiça, da imparcialidade e da boa fé, enunciados no ํㅡ 2, do art. 266ํ da CRP. Embora, como deixamos dito, entendamos que não se trata aqui de actos políticos, mas de actos administrativos, aceitando todavia que se pode tratar de actos praticados ao abrigo da já referida margem de escolha política da Administração, e cuja legitimidade apenas pode ser averiguada através da sua compatibilidade a princípios jurídicos fundamentais, consideramos que essa violação não tem que se revelar crassa ou evidente para justificar a intervenção do tribunal (ressalvando a eventual dificuldade do decisor judicial em reunir todos os elementos que the permitam proceder a essa valoração). Um tal reconhecimento equivale a conceder aos órgãos administrativos e decisores uma margem de manobra só susceptível de ceder perante a óbvia constatação da desadequação do meio, da sua desproporcionalidade, desigualdade, ou da violação do núcleo essencial dos direitos. Não nos parece sequer que esta posição ande longe da que é sustentada por Medeiros R (13), onde manifesta a sua concordância com a posição defendida por Reis Novais, no sentido da aceitação de um controlo alargado de constitucionalidade

... de todos os comportamentos públicos susceptíveis de lesar as possibilidades de prosseguimento dos fins pessoais garantidas por um direito fundamental, sujeitando-os a parâmetros de constitucionalidade comuns, evitando que, em última análise, a Constituição do Estado de Direito e os equilíbrios nela delineados acabam por sair penalizados" (...) "adopta-se um conceito amplo de restrição aos direitos fundamentais, entendida como acção ou omissão estatal que, eliminando, reduzindo, comprimindo ou dificultando as possibilidades de acesso ao bem jusfundamentalmente protegido e a sua fruição por parte dos titulares reais ou potenciais do direito fundamental ou enfraquecendo os deveres e obrigações que dele resultam para o Estado, afecta desvantajosamente o conteúdo de um direito fundamental (32)

O que sucederia, por exemplo, onde, perante um caso desta natureza, o Governo, ou a Administração, resolvesse deixar apenas em funcionamento uma maternidade no Porto, e outra em Lisboa. Convém, todavia, lembrar que, mesmo onde constate a violação de princípios jurídicos fundamentais por parte do decisor administrativo, o tribunal apenas procede a essa constatação, vale dizer, a um controlo de índole negativa, não se podendo substituir às valorações e escolhas feitas pela Administração, pelo que não se coloca o 
problema que aflige o ordenamento jurídico brasileiro e o seu sector da saúde, e que se relaciona com a imposição de formas de actuação aos órgãos administrativos.

Regressando ao princípio regulativo da razoabilidade, e muito embora, como dissemos, não possa ser elevado à categoria de princípio jurídico capaz de garantir o controlo adequado das decisões concretas da Administração, ele pode apesar de tudo permitir, como expressão de um juízo global, concluir do acerto da valoração feita acerca do equilíbrio e proporcionalidade de uma determinada decisão orçamental ou política à luz das valorações do ordenamento constitucional e dos seus princípios fundamentais (principio da dignidade humana, da igualdade e da liberdade das pessoas), tendo em conta a posição que ocupa o direito á saúde no contexto da tutela dos direitos fundamentais, quer enquanto direito social, quer enquanto direito que substancialmente diz respeito a direitos que não estão sujeito ao limite da "reserva do possível", e os pressupostos a que está sujeita a restrição legal dos direitos, liberdades e garantias de acordo com o $n^{\circ} 2$, do art. $18^{\circ}$, da CRP.

Deixamos para o fim o tratamento do problema do direito à saúde em relação a doentes terminais e sem esperança de cura. Não nos parece que se deva alterar uma linha do nosso discurso em relação a estes casos, sendo de manter o que ficou dito em relação ao uso de critérios de necessidade e de utilidade terapêutica. O mesmo critério da necessidade e utilidade terapêuticas deve ser utilizado em relação aos doentes terminais, e aos doentes sem esperança de cura. Nestes casos, o medicamento ou o procedimento já não é muitas vezes medicamente indicado, não se deixando já associar a sua administração ou execução a qualquer benefício ou vantagem que supere inclusivamente os riscos e os incómodos da sua administração, pelo que se trata da administração de um tratamento fútil, não sendo sequer necessário discutir critérios de alocação de recursos. Diferente desta hipótese, é aquela em que o tratamento ainda é útil, ou do doente terminal que carece de cuidados paliativos de certo tipo que podem ser muito dispendiosos, caso em que devem ser utilizados os mesmos critérios que valem para os outros doentes em geral, devendo a valoração da situação estar sujeita ao funcionamento do princípio da igualdade de tratamento. Contrariaria princípios básicos de dignidade e de humanidade, a introdução de critérios utilitaristas ou estritamente económicos no discurso de racionamento ou distribuição de meios em relação a estes doentes. 


\section{Considerações Finais}

As decisões de gestão de recursos que afectam direitos relacionados com a saúde não são decisões aleatórias, nem correspondem a uma distribuição episódica e trágica de injustiças. Devem ser consideradas decisões de natureza administrativa, condicionadas ao cumprimento da Constituição e da lei, e dos princípios constitucionais que orientam a restrição de direitos fundamentais. Uma vez que a nossa lei consagra o direito à saúde através da Lei de Bases e outras normas, que estendem para o plano do direito ordinário a tutela dos direitos e princípios constitucionais (veja-se o que se disse atrás, acerca da tutela infra constitucional dos direitos), a violação do conteúdo deste direito através de decisões de corte e suspensão de serviços e de medicamentos, quando não estiver de acordo com os princípios e as ponderações referidas, deve ser apreciada pelos tribunais, sobretudo nos casos em que está em causa o direito à vida e a tratamentos de emergência (ou seja, onde se tocam mais de perto direitos essenciais relacionados com a protecção da saúde). A discussão sobre se está em causa uma actividade vinculada da Administração, ou uma decisão de natureza discricionária, não interessa verdadeiramente, na estrita medida em que está em discussão o desrespeito dos princípios jurídicos fundamentais que regem a sua actividade. Os tribunais terão mesmo um papel muito importante a desempenhar neste domínio, cabendo-lhes desenvolver interpretativamente estes princípios, dado que as decisões que estão em causa, pela importância que assumem, e pelos direitos que podem afectar, não podem ser consideradas juridicamente insindicáveis, abandonadas em campo aberto à discricionariedade médica e orçamental das instituições e dos serviços.

\section{Referências}

1 Base V, no 1, da Lei de Bases da Saúde, Lei no 48/90, de 24 de Agosto (actualizada pela Lei $n^{\circ}$ 27/2002, de 11 de Novembro), que estabelece o seguinte:."Os cidadãos são os primeiros responsáveis pela sua própria saúde, individual e colectiva, tendo o dever de a defender e promover"

2 Furtado C, Pereira J. Equidade e acesso aos cuidados de saúde. Lisboa: Universidade Nova de Lisboa; 2010. p. 4

3 Lei nº 21/2014, de 16 de Abril, Lei da investigação clínica 
4 Vieira de Andrade, JC. Os Direitos Fundamentais na Constituição Portuguesa de 1976, 4 ed. Coimbra: Almedina; 2009. p. 384 e ss.

5 Pieterse M. Health Care Rights, Resources and Rationing. African Law Journal; 2007. p. 530

6 Sérvulo Correia. Direito do Contencioso Administrativo, Volume I. Lisboa: Lex, 2005. p. 777

7 Fontes J, Fonseca G, Claro J. Código de Processo nos Tribunais Administrativos e Legislação Complementar, 5 ed. Coimbra: Almedina; 2011

8 Constituição da República Portuguesa, 2 ed. Coimbra: Almedina; 2015

9 Miranda J e Medeiros R. Constituição Portuguesa Anotada, Tomo I, anotação ao art. 64², $2^{\mathrm{a}}$ ed. Coimbra: Wolters Kluwers/Coimbra Editora; 2010. p..1305 e ss.

10 Miranda J. Ética Médica e Constituição. Revista Jurídica. Lisboa: Nova Série 16 - 17; 1992

11 Brito Vieira M, Carreira da Silva F, O momento constituinte - os direitos sociais na Constituição, Coimbra: Almedina; 2010

12 Gomes Canotilho, Vital Moreira. Constituição da República Portuguesa Anotada, 3 ed. Coimbra: Coimbra Editora; 1993.

13 Medeiros R. A Constituição Portuguesa num Contexto Global. Lisboa: Universidade Católica Editora; 2015. p. 107

14 Lei de Bases da Saúde. Lei oํ 48/90, de 24 de Agosto, actualizada pela Lei oㅡ 27/2002, de 8 Novembro

15 Lei ํㅜ 56/79, de 15 de Setembro, Serviço nacional de saúde

16 Lei oํ 11/93, de 15 de Janeiro, Estatuto nacional de saúde (veja-se, na versão mais recente, a Lei oㅡ 82-B/2014, de 31 de Dezembro)

17 Lei no 15/2014, de 21 de Março, Direitos e deveres do utente dos serviços de saúde

18 Lei no 14/2000, de 8 de Agosto, Medidas para a racionalização da política do medicamento no âmbito do Serviço Nacional de Saúde

19 Arnaut A; Mendes M; Guerra M; Serviço Nacional de Saúde: uma aposta no futuro. Coimbra: Atântida Editora. 1979 
20 Portugal. Lei de Bases da Saúde, Lei oㅡ 48/90, de 24 de Agosto:"A promoção da saúde e a prevenção da doença fazem parte das prioridades no planeamento das actividades do Estado".

21 OMS. Conferência Internacional de Saúde, Nova lorque, 19-22 de junho. 1946. Assinada a 22 de julho de 1946 pelos representantes de 61 Estados (registos oficiais da OMS, no 2, p. 100) tendo entrado em vigor a 7 de abril de 1948.

22 Reis Novais J. Direitos Sociais - Teoria Jurídica dos Direitos Sociais enquanto Direitos Fundamentais. Coimbra: Coimbra Editora; 2010. p. 161

23 Portugal. Código Penal Português. Coimbra: Coimbra Editora; 2015.

24 Lei ㄲo 67/2007, de 31 de Dezembro. Lei da Responsabilidade civil extracontratual do Estado e pessoas colectivas de direito público

25 Lamm R. Misallocating Health Care and Societal Resources. Notre Dame, Journal of Law, Ethics \& Public Policy. 1987. p. 241.

Recebido em: 5/8/2016 Aprovado em: 12/12/2016

Como citar este artigo:

Faria MPLR. Acesso à inovação - investigação, ética, médica, direitos dos doentes e recursos financeiros. Revista Cadernos Ibero-Americanos de Direito Sanitário. 2016 dez., 5 supl. 1:100-128. 